\title{
Hydrological function of berms within a waste landform design
}

\author{
B Roddy Landloch Pty Ltd, Australia \\ E Howard Landloch Pty Ltd, Australia
}

\begin{abstract}
Berms remain a persistent feature in waste dump landform designs as they are perceived to provide the benefits of reduced slope length, protection against future batter erosion by partitioning the slope with level or backsloping berms, and reduced flow velocity. Underpinning this rationale is the belief that the berms will be a permanent and unchanging feature that controls erosion over the long term. These assumptions are not true. Berms begin to evolve immediately after their construction by trapping sediment and having a beneficial effect over the short to medium term. Longer term, berms fill with sediment and overtop. The time it takes to overtop depends on the material, the size of the berm, and the climate. Once a berm is breached, previously hydraulically disconnected batter sections become a connected flow network that delivers large volumes of runoff from upper slopes to lower slopes that were never designed to withstand them. This process can be caused, or contributed to, by poor quality construction techniques.
\end{abstract}

\section{$1 \quad$ Introduction}

A common configuration used for waste landform batter designs is the construction of steeply sloping linear batters that are partitioned by berms that have zero gradient or are backsloping (Figure 1). Batters are often constructed in lifts that typically range in height from 10-20 m, are regraded to closure gradients of $15-20^{\circ}$, and utilise berm widths of $5-10 \mathrm{~m}$ with a backslope of rarely more than $5^{\circ}$. Lift heights commonly align with the heights constructed during operations. This configuration continues to be commonly utilised.

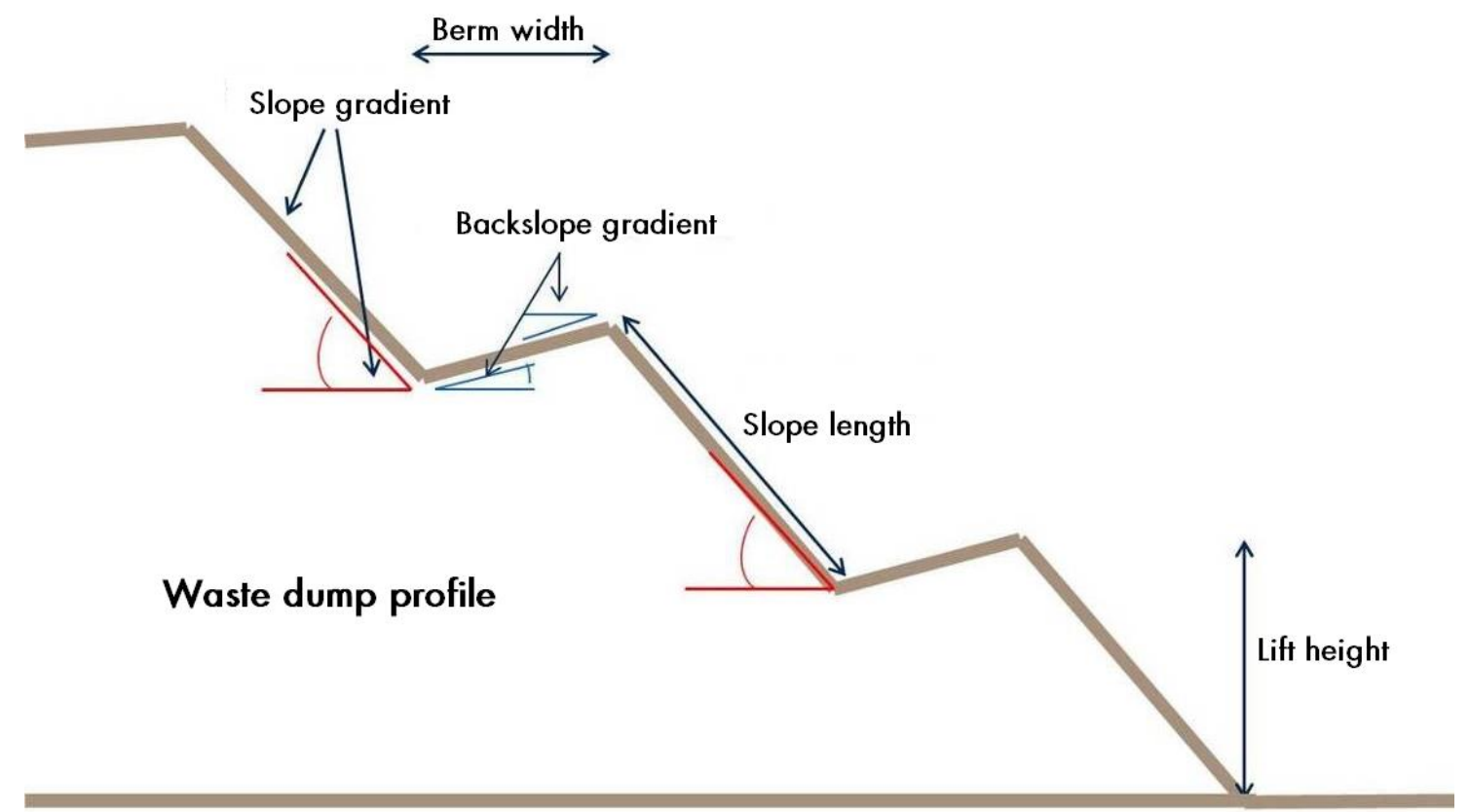

Figure 1 Common batter/berm waste dump configuration and common terminology 
It is the authors' observation that batter/berm landform configurations fail (Figure 2). Risks and consequences associated with the presence of berms on waste landforms have been previously documented (Loch \& Willgoose 2000; Vacher et al. 2004; Loch \& Vacher 2006; Stevens 2006; Howard et al. 2010).

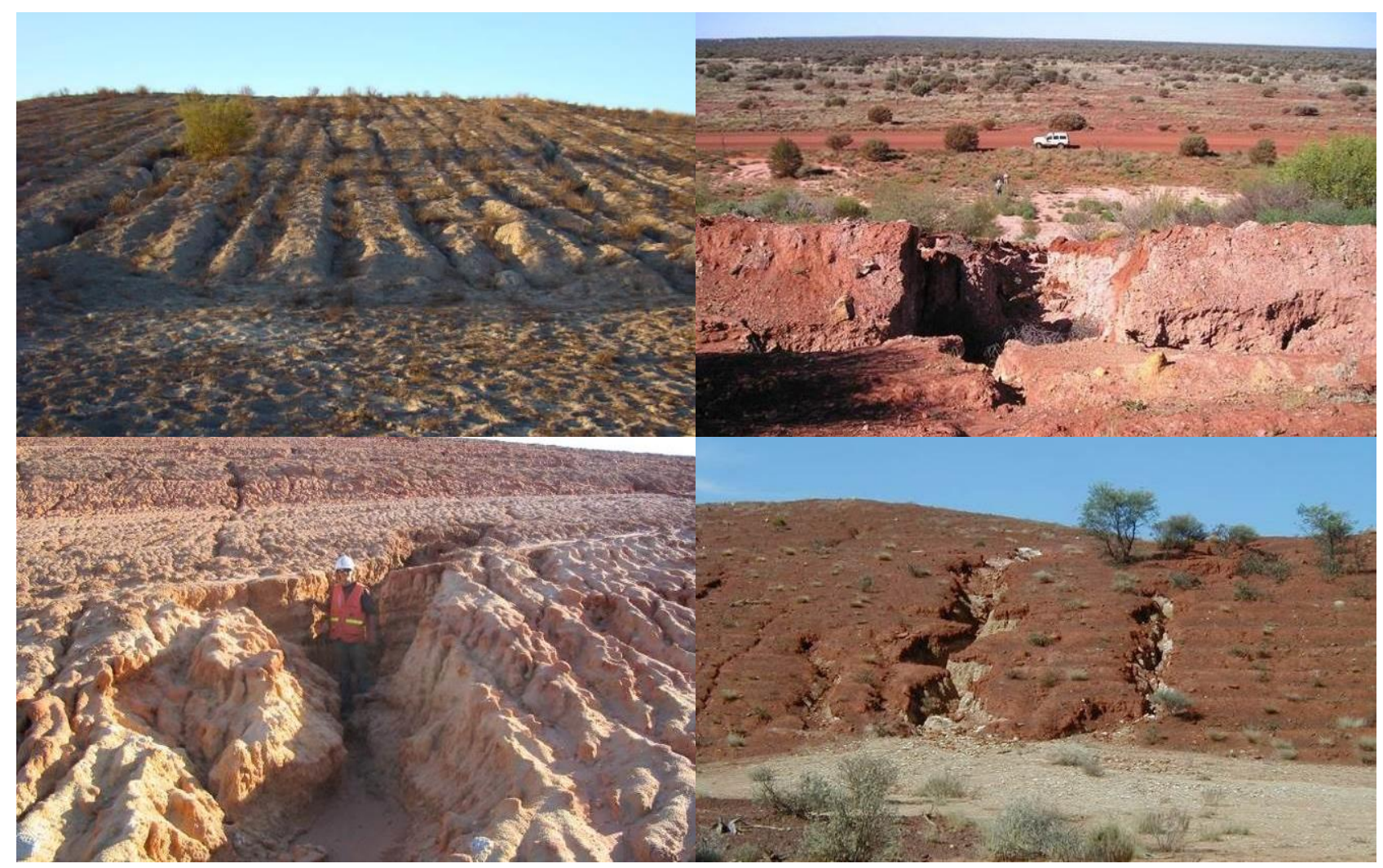

Figure 2 Examples of waste landform batter and berm design failures from across Australia

The mechanisms for berm failure are known, though not fully appreciated by the industry. The authors have observed three main mechanisms.

Firstly, berms act to trap and store eroded sediment and infiltrate runoff from upslope batter sections. The repeated deposition of eroded sediment decreases the storage capacity of the berms. Once the capacity of the berm to store both the deposited sediment and runoff generated from upslope areas during rain events is exceeded, the berms overtop and discharge water flows from the upslope batter lifts to lower lifts at discrete points, creating large rills and gullies on the lower batters (Figure 3 ). This in turn results in the berms positioned lower than the failed berm to more rapidly fill with sediment, and to have to manage runoff from more than one upslope batter section. Once one berm fails, the lower berms fail at an accelerated rate. Avoidance of rills and gullies is critical to achieving rehabilitation success, given that erosion from them typically accounts for $75-85 \%$ of total erosion from a slope (Govers \& Poesen 1988).

Secondly, if not constructed level (that is, on a constant level), berms encourage the lateral movement of ponded runoff to concentrate at a low point on the berm: where it then overtops. This can cause large erosion features, even if the capacity of the berm to store sediment and runoff is otherwise satisfactory. A similar process can occur when uncontrolled discharge is allowed from dump tops (Figure 3 ). This failure mechanism is caused either by poor control over the accuracy of construction or by poor dump planning.

Thirdly, ponding of runoff on a berm constructed from tunnel-prone materials encourages tunnelling of the berm. These tunnels can themselves convey water from one lift to another, and eventually collapse in on themselves and create 'instant gullies' (Figure 4).

Another possible mechanism of failure is a mass failure (slip failure) of the berm caused by excessive ponding on the berm. 


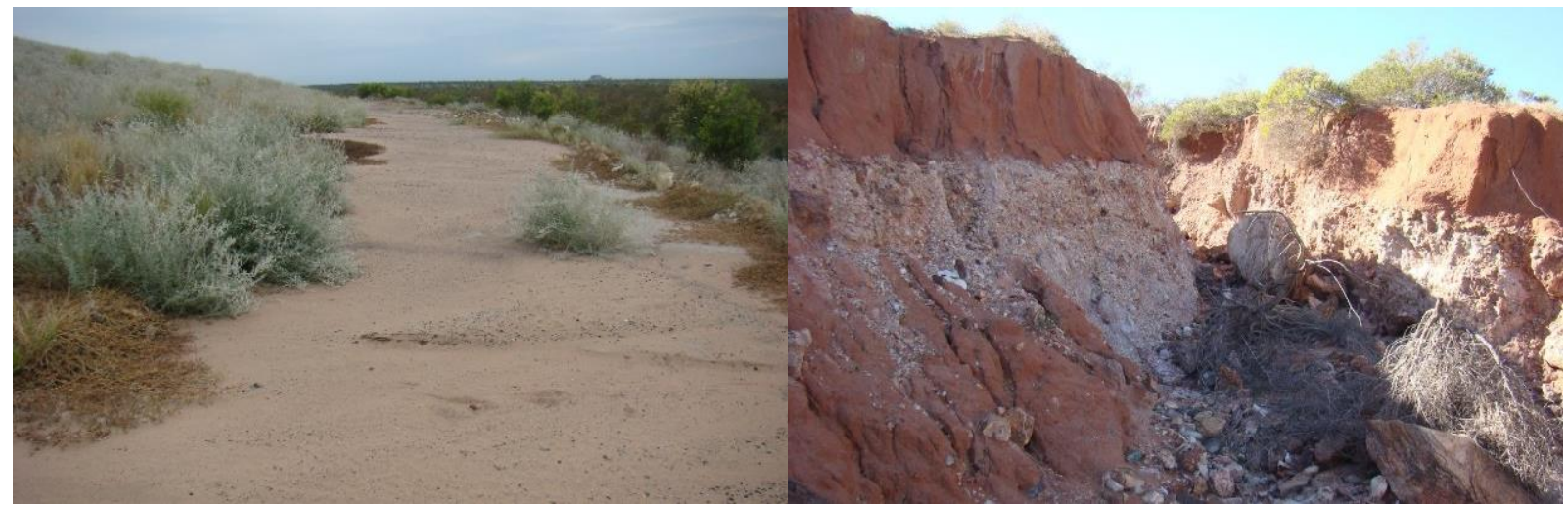

(a)

(b)

Figure 3 (a) Back sloping berms filling with sediment; (b) ponded dump top runoff overtopping and discharging to batter slopes

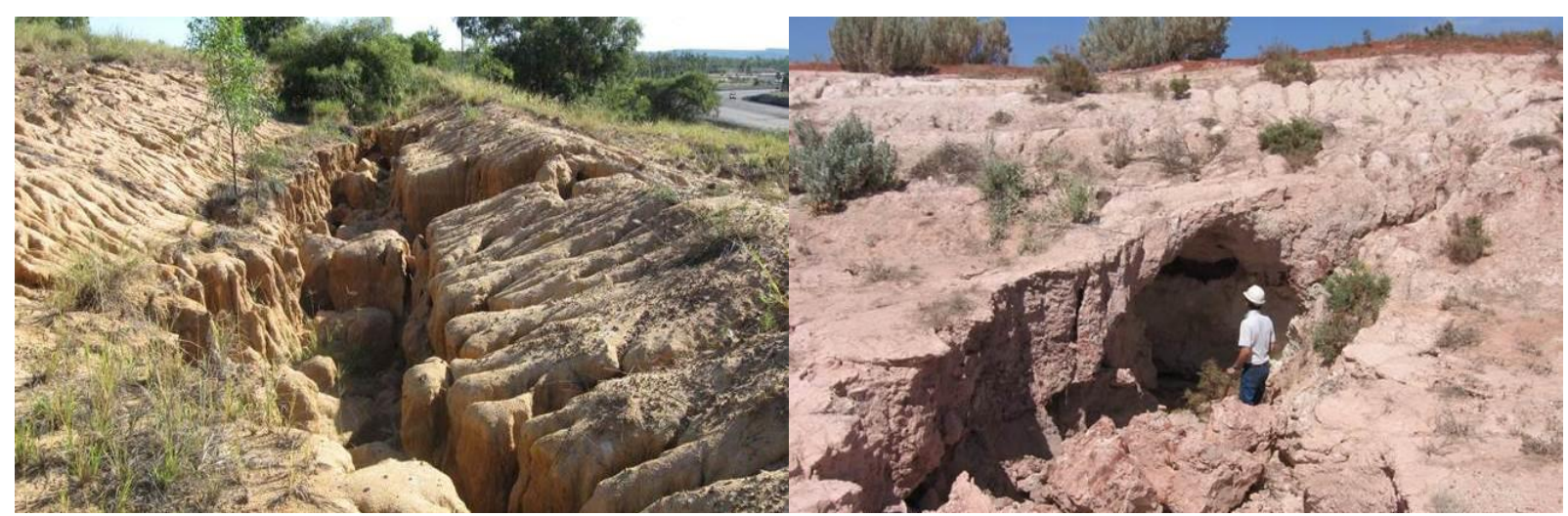

Figure 4 Tunnel failure on berms constructed with tunnel-prone material

\section{Rationale and assumed benefits of the use of berms}

It is the authors' observation that although berms remain a common feature of mining landforms, the rationale of their use is rarely considered. This has led to the underlying principles for their use being not clearly understood, and assumptions not being thought through.

A set of principles for the use of berms has not (to the authors' knowledge) been previously documented. Based on discussions with numerous mining personnel, the rationale for the use of berms in landform designs is strongly linked to the assumptions that:

- Slope length is a critical driver of soil erosion and increasing slope length invariably causes an increase in erosion.

- Berms can adequately manage the runoff and sediment generated from the upslope section.

- Berms 'slow the flow' and limit erosion on slopes by decreasing runoff velocities.

These assumptions lead to the following anticipated benefits:

- Berms break up a long batter slope length and reduce erosion potential on each batter section.

- Runoff accumulation is controlled on each batter, and slope lengths are never long enough for high erosion rates to occur.

- Berms provide areas of decreased flow velocity and areas of sediment deposition.

- If rilling or gullying does occur on a particular batter section, a berm will quarantine the lower lifts from the gully continuing unimpeded down the slope. 


\section{$3 \quad$ Challenging the rationale and assumed benefits}

The principles and presumed benefits are based on a superficial understanding of erosion processes, and an often unfounded reliance on the effectiveness and longevity of the engineered berm structure. In many cases, berms are simply not needed to minimise erosion, and where they are of benefit, they must be designed to withstand extreme runoff events (and the sediment generated), and constructed to a high standard if they are to be functional.

\subsection{Assumption \#1: Erosion rate increases with slope length}

Slope length is indeed an important factor in the erosion potential of a batter slope. However, other factors also contribute to the erosion potential of a batter, and hence the requirement or otherwise for a berm. These factors include climate (in particular rainfall characteristics and the resulting runoff), the properties of the surface materials, and slope gradient. The different effects of these factors are non-linear and illustrated with an example, in Figures 5 and 6 in which the Water Erosion Prediction Project (WEPP) model was used to predict erosion. WEPP is capable of predicting erosion in a mine setting, provided the model is well calibrated. Howard and Roddy (2012) give an evaluation of the WEPP model and provide validation data for 11 mine site batters (Figure 7).

In the example, erosion from a soil from the Western Australian (WA) Goldfields is compared with erosion from the same soil when waste rock from the mine was added to the surface. The same soil is also considered using a climate file for the arid WA Goldfields, and Port Hedland in WA, where more rainfall occurs and that rainfall is dominated by intense cyclonic events. Climates are shown in brackets in Figures 5 and 6.
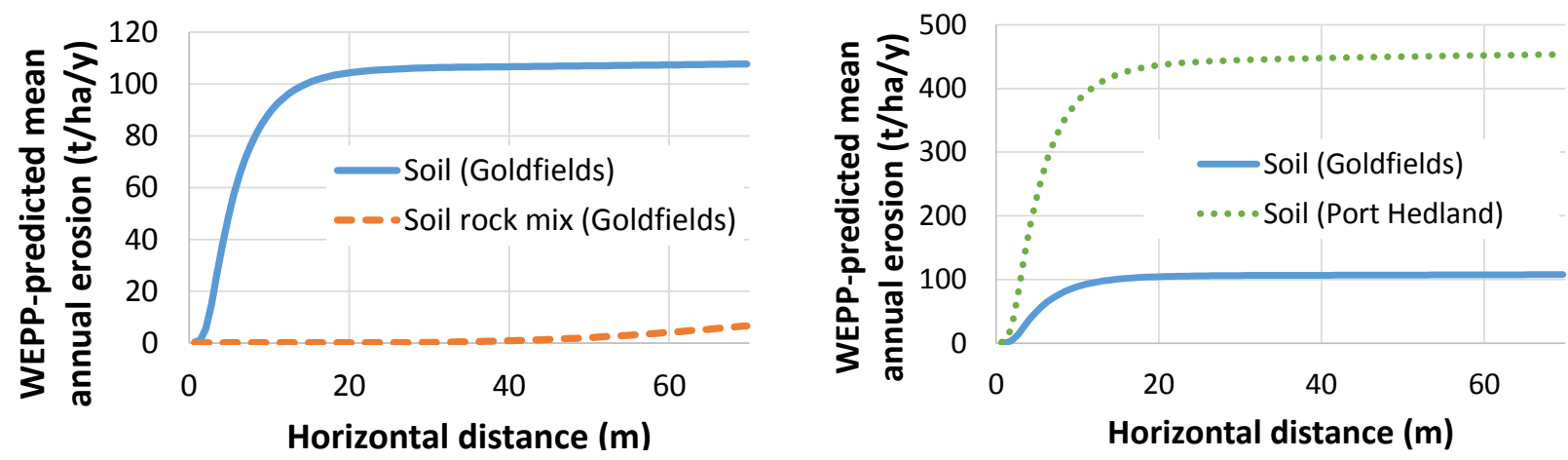

Figure 5 WEPP-predicted erosion rates for a $20 \mathrm{~m}$ high, $16^{\circ}$ linear batter with various sheeting materials and climate combinations (climate shown in brackets)
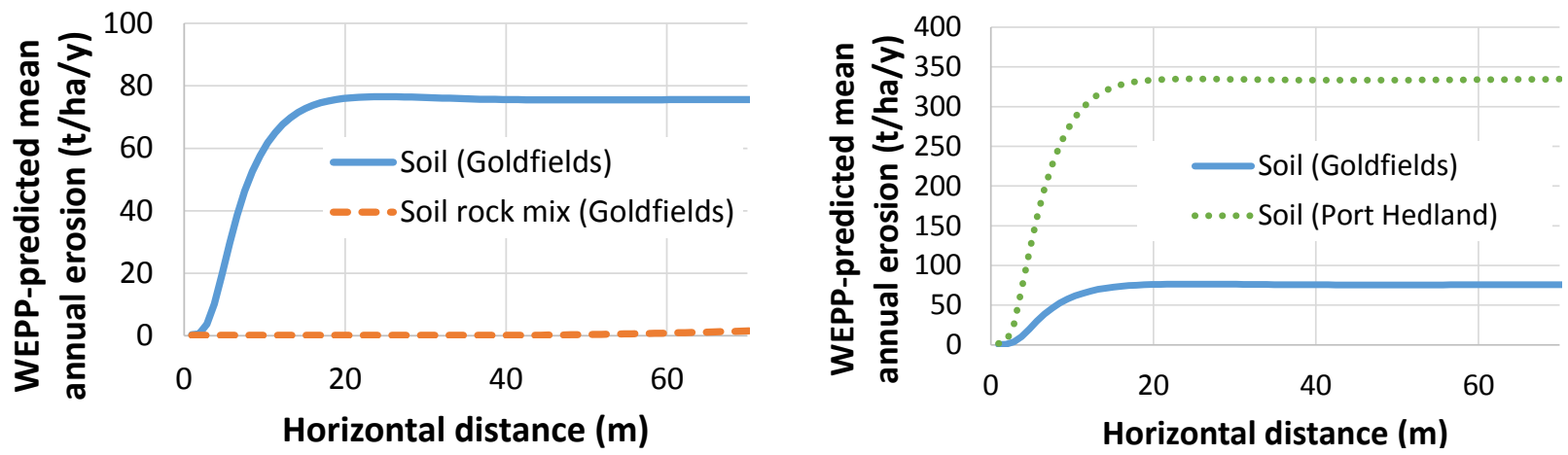

Figure 6 WEPP-predicted erosion rates for a $20 \mathrm{~m}$ high, $12^{\circ}$ linear batter with various sheeting materials and climate combinations (climate shown in brackets) 


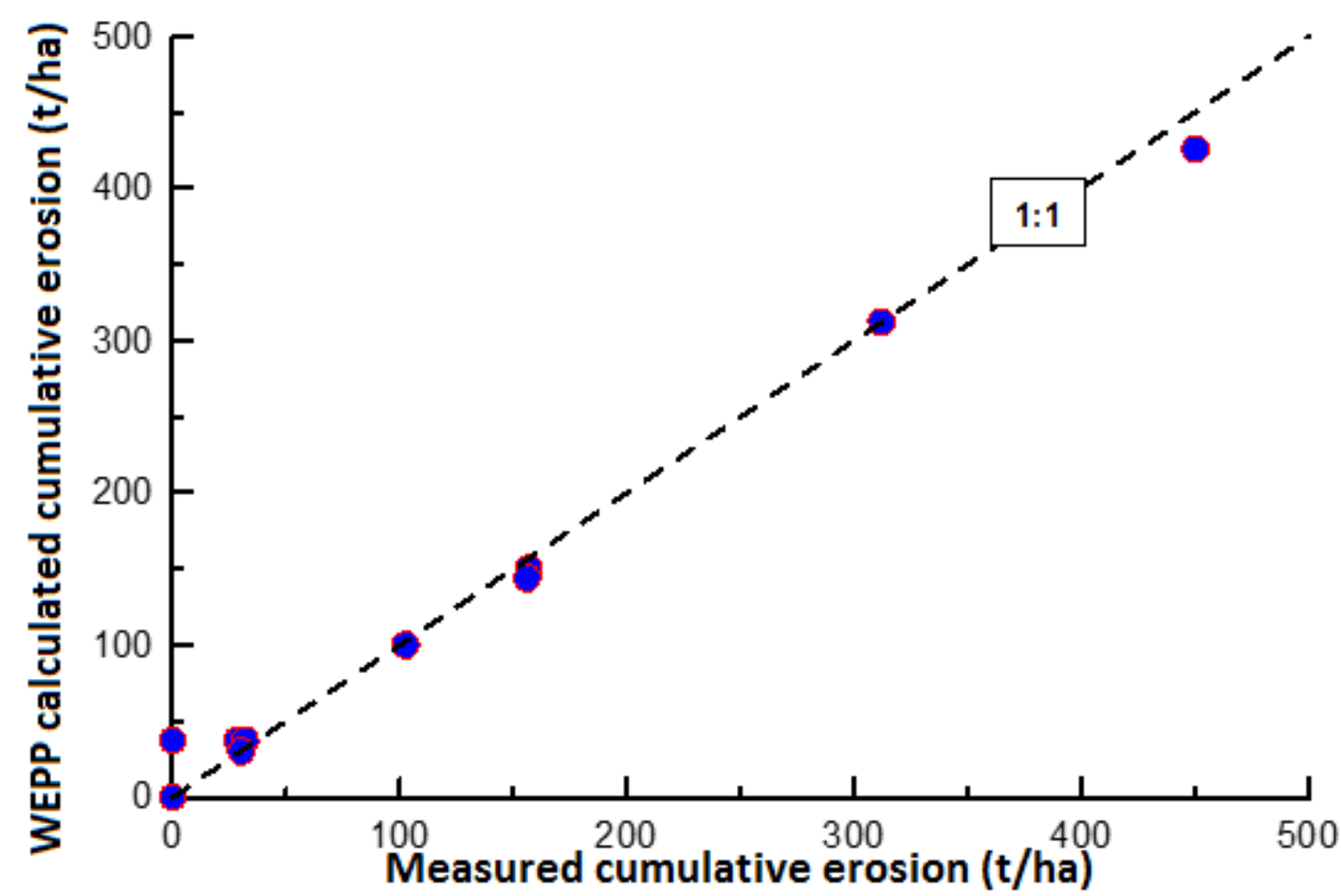

Figure 7 Calculated and measured cumulative erosion rates for 11 batter slope locations in mines in Western Australia (reproduced from Howard \& Roddy 2012)

These results clearly illustrate that actual erosion rates are strongly dependent on material type, climate, slope gradient, and slope length. This has been found to be true by the authors, based on assessment of erosion of hundreds and wastes, tailings, and soils sourced predominantly from mines across Australia, but also from sites across the world.

For the Soil material, detachment occurs easily and erosion rapidly increases over very short slope lengths. For this material and for both the climate and gradient considered, erosion is controlled by the capacity of runoff to transport the eroded sediment. For the Soil-Rock-Mix material, erosion is not controlled by the transport capacity, but rather by the shear stress required to cause detachment. For both the gradients and climate shown, this material is predicted to not erode, even though slope lengths of $70-100 \mathrm{~m}$ are considered.

This highlights two important limitations in the assumption that erosion increases with slope length.

Firstly, for some combinations of material, gradient, and slope length, erosion may not occur at all. This will mean that berms could potentially not be required at all for some material, e.g. the Soil-Rock-Mix material. Given that berms, if properly constructed, cost tens of thousands of dollars per hectare to create, this could be a cost that may be avoided.

Secondly, use of berms set at the typically adopted batter lengths (e.g. 10-20 m vertical heights) may provide no real benefit in controlling erosion. This is demonstrated in the predictions of erosion for the Soil material (Figure 5). For berms to be effective at all in this material, lift heights of 1-2 $\mathrm{m}$ would need to be adopted (which is clearly not practical).

The same findings were demonstrated in the field by the authors on large scale erosion plots at the Nifty Copper Mine in the east Pilbara region of WA (Robinson et al. 2014). At this site, plots covered in sandy topsoil or a mixture of sand and oxide were observed to erode at slope lengths of less than $5 \mathrm{~m}$ while batters sheeted in oxide were quite stable over the same slope length (Figure 8). This clearly demonstrates that berms are of little benefit in controlling erosion for the sandy material or the mixture of sand and oxide. 


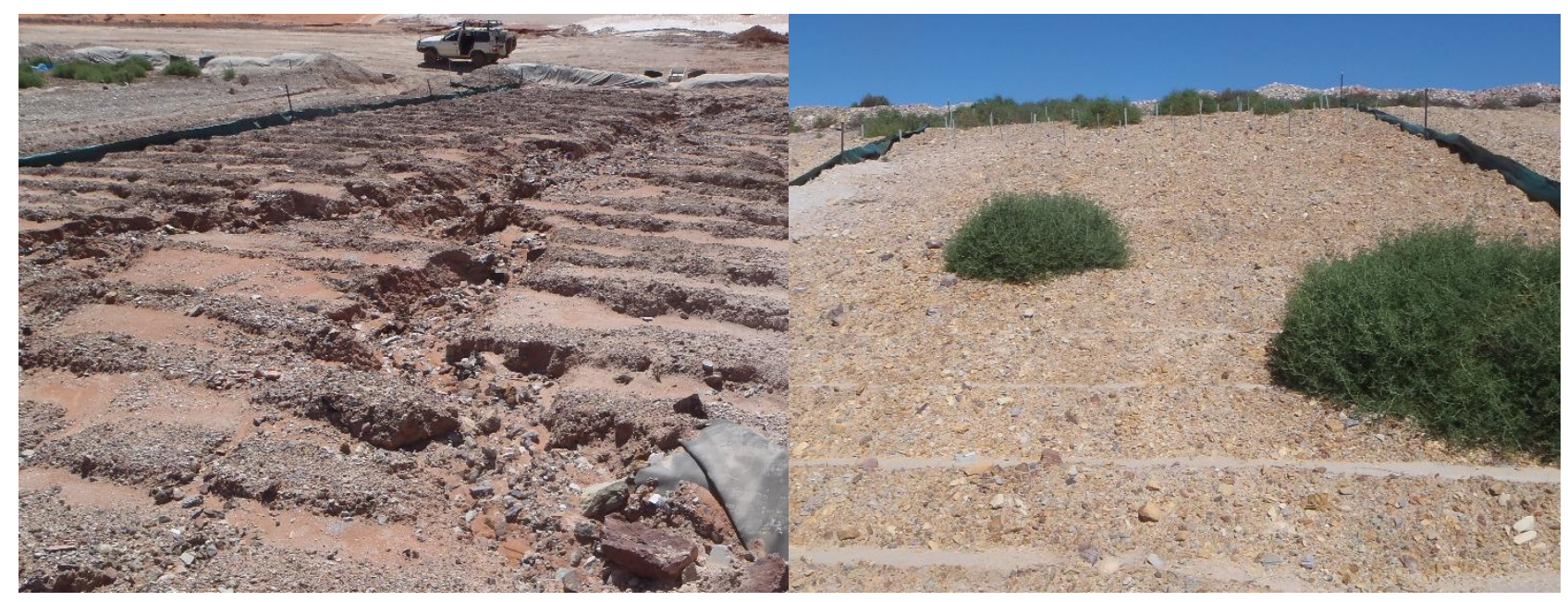

(a)

(b)

Figure 8 Sand and oxide cover erosion plot (a) eroding on slope lengths of less than $5 \mathrm{~m}$, compared to an oxide covered plot (b) that was quite stable for the same slope length

Another example was reported by Howard and Lowe (2014) in which a marine dredge spoil was shown to erode at lift heights of $\sim 5 \mathrm{~m}$. Stabilisation of this site required removal of the berm, and incorporation of a durable rock into the surface (Figure 9).

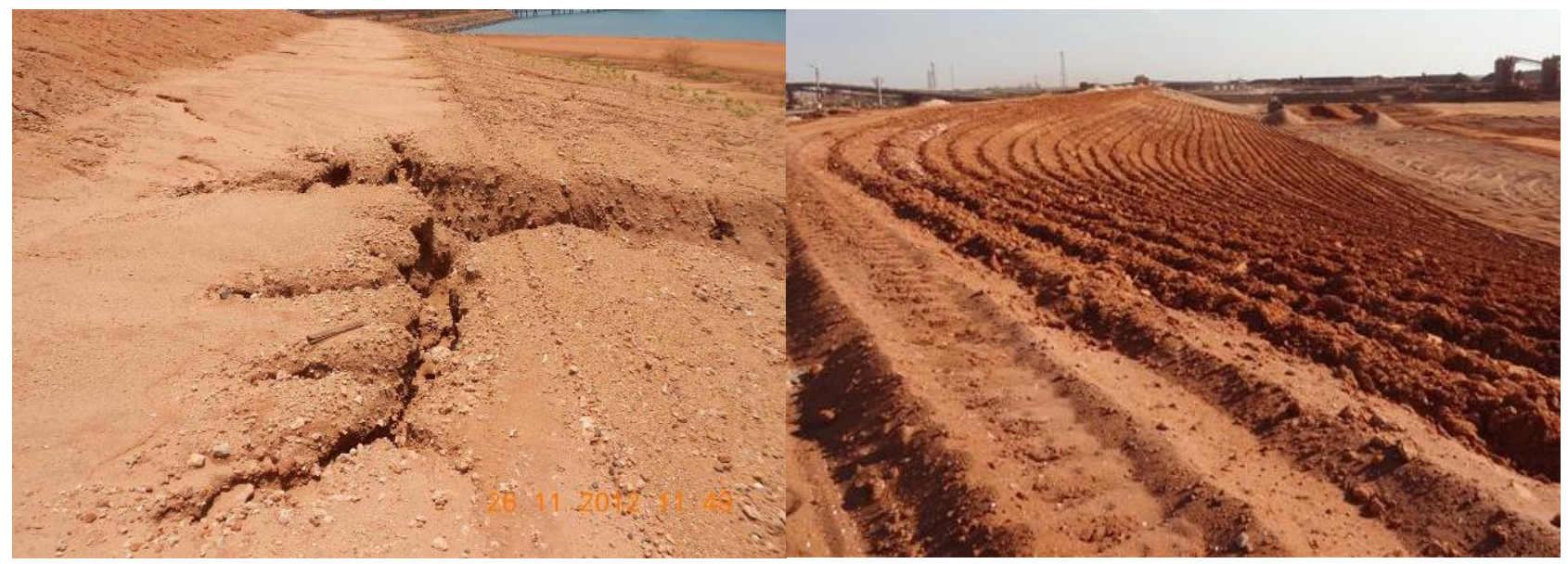

(a)

(b)

Figure 9 (a) Rehabilitation of a marine dredge spoil bund showing failed berm; (b) reshaping to remove berm and add rock into the surface

\subsection{Assumption \#2: Berms manage runoff and sediment in the long term}

\subsubsection{Berm storage capacity}

It is often assumed that berms provide long-term protection against erosion by storing sediment and managing ponded runoff within them such that the berms are never breached or never overtop.

Berms are often built without any consideration of their required design life, and if design is considered, it is often based on an average recurrence interval of 100 years. Clearly, having no design basis carries a high risk, and often leads to berms that are very narrow and not backsloping. Their capacity is often dictated by widths set by mine planning decisions based on optimising dump capacity (with inadequate thought for closure requirements). For the situation where a design life is based on an average recurrence interval of 100 years, the designed berm will have a $1 \%$ chance of failure every year. When considered over a 20 year period, this equates to a $\sim 17 \%$ chance that the berm will be breached once. If a 50 year period is 
considered, the probability is $\sim 30 \%$. After 100 years, the probability of failure is $\sim 37 \%$. If a 200 year recurrence interval is used, there is still a $\sim 30 \%$ chance of failure after 100 years.

The frequency of berm failure was considered using the WEPP model to predict sediment deposition rates into a 5\% backsloping berm generated from a $20 \mathrm{~m}$ high, 18 degree linear batter sheeted with a range of topsoils for which calibrated erodibility data were available. Erosion predictions were made using climate data for the same region from which the calibrated soils data were sourced. A range of berm widths were considered. The results are given in Table 1 . The results show that the longevity of a berm is highly variable, and strongly controlled by both the material type and the climate. Therefore, adoption of standard berm widths is likely to be of limited value.

Table 1 WEPP-predicted berm longevity for a range of soils and climates ( $\%$ backslope assumed)

\begin{tabular}{cccccc}
\hline \multirow{2}{*}{$\begin{array}{c}\text { Berm } \\
\text { width }(\mathrm{m})\end{array}$} & \multicolumn{4}{c}{ Number of years before filling of berm capacity, for soil and climate from the: } \\
\cline { 2 - 6 } & Tanami & Pilbara & Goldfields & Southwest WA & Kimberley \\
\hline 5 & 52 & 25 & 2 & 6 & 1 \\
10 & $>100$ & 63 & 17 & 23 & 1 \\
15 & $>100$ & $>100$ & 31 & 45 & 3 \\
\hline 20 & $>100$ & $>100$ & 46 & 78 & 6 \\
\hline
\end{tabular}

These data indicate that the use of berms to manage water contains a risk that failure will occur. It is the authors' observation that once a berm has been breached, concentrated flow lines establish that rapidly and irreversibly alter the hydraulic function of the berms. Figure 10 demonstrates this, using an example of long-term landscape evolution modelling (SIBERIA) output for a soil from the Goldfields region of Western Australia.

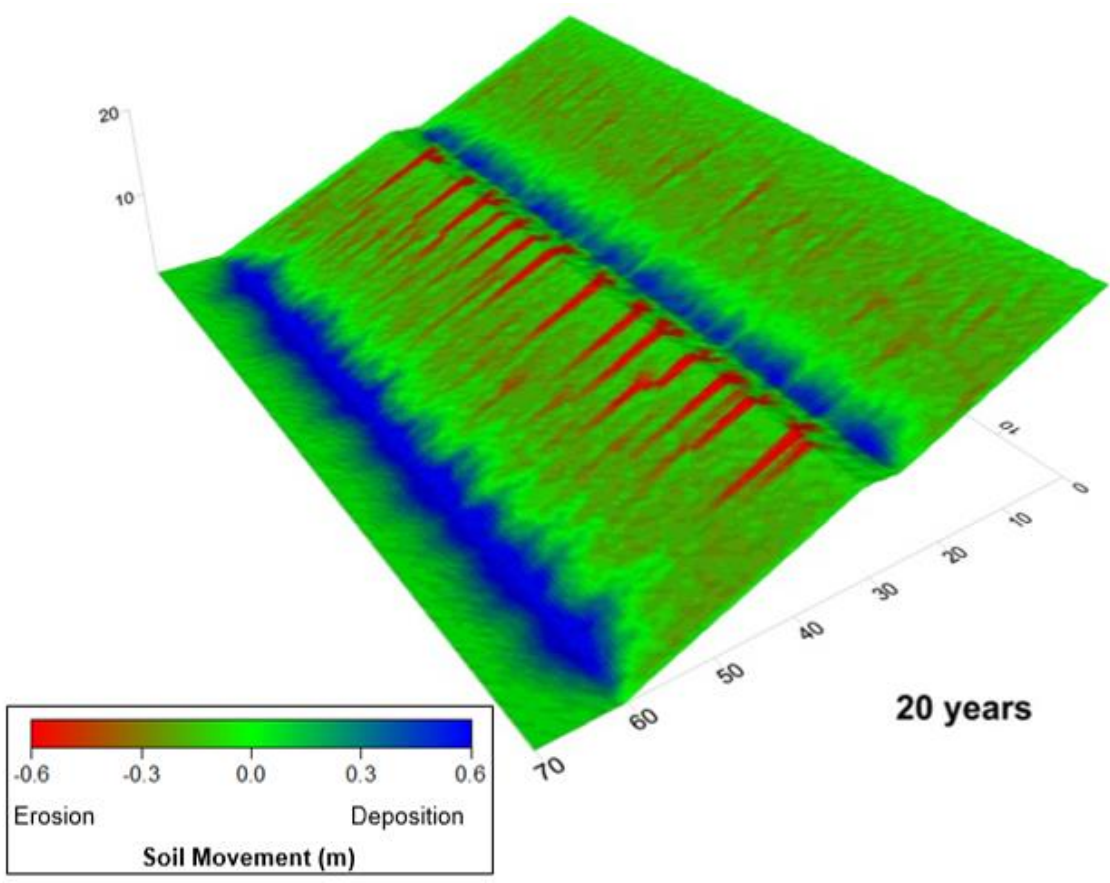

Figure 10 SIBERIA output for two $10 \mathrm{~m}$ high topsoiled batters with gradient of $20^{\circ}$, separated by a $5 \mathrm{~m}$ back-sloping berm after 20 years (under Goldfields climate)

The example shows a $20 \mathrm{~m}$ high dump sheeted with a topsoil material with two $10 \mathrm{~m}$ high batters of $20^{\circ}$ separated by a $5^{\circ}$ backsloping berm $5 \mathrm{~m}$ in width (a common configuration). Of note is that this SIBERIA output is only after 20 years. 
Once a berm is breached, the two batter slopes become hydrologically connected, and as a result the erosion on lower batters will change. This is demonstrated by WEPP simulations shown in Figure 11. For the upper lift (shown as the horizontal distance 0-95 m) the erosion predictions are the same for the breached and unbreached berm. However, for the breached berm, the predicted rate of erosion is almost four times higher than that for the unbreached berm.

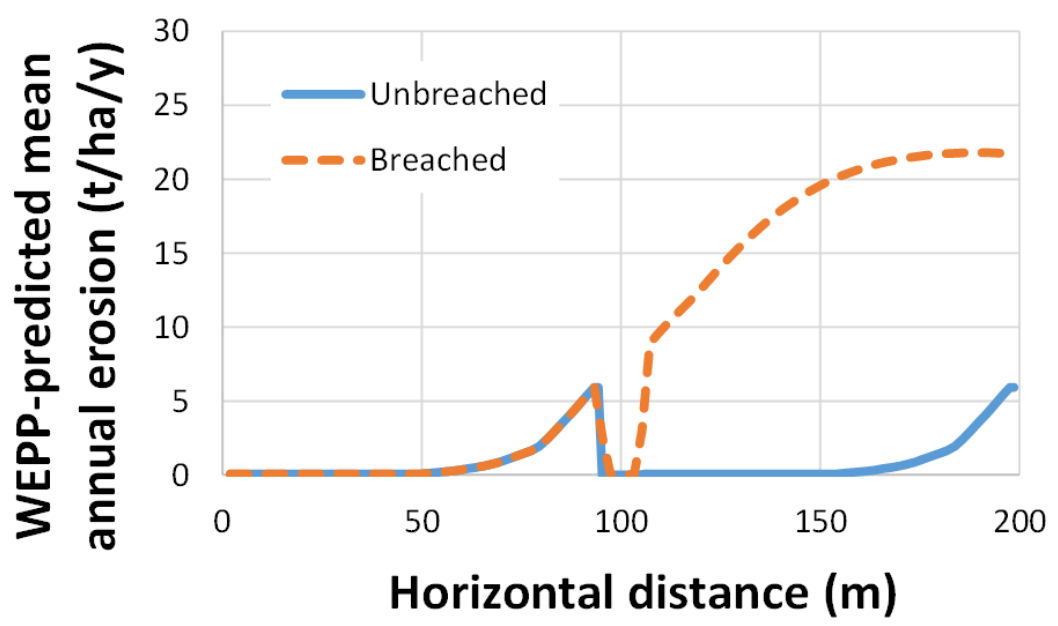

Figure 11 WEPP-predicted erosion for a $2 \times 20 \mathrm{~m}$ high, 12 degree batter slopes, separated by a $10 \mathrm{~m}$ wide berm and sheeted in rocky soil near Newman. Results show results for a breached and unbreached berm

\subsection{Assumption \#3: Berms 'slow the flow'}

The authors have frequently observed that it is assumed that berms reduce the flow velocities of runoff on a batter and, as a result, decrease the erosion potential. While this is true for the scenario where the berm has not been breached, it is not true in the case where breaching has been occurring and runoff is discharging as concentrated flows from one lift to another through a berm.

For a breached berm scenario, the resultant changes in hydraulic parameters are shown conceptually in Figure 12.

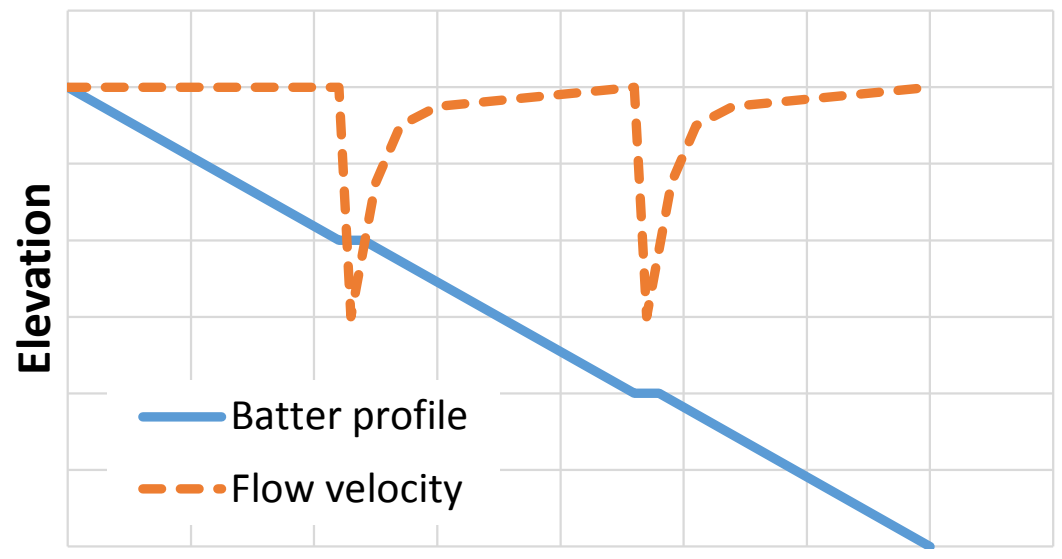

Horizontal distance

Figure 12 Conceptual changes in runoff velocity in response to a batter and berm configuration

At the toe of the batter where water discharges to the berm, there is a marked decline in flow velocity. However, at the crest of the next batter, the velocity of runoff rapidly increases until it returns to rates previously reached on the upslope batter above the berm. Berms do not reduce water velocity on the vast majority of the batter slope length. This rapid increase in flow velocity will also cause turbulent flow which causes scour at the batter crest, further exacerbating the effects of the concentrated flow. 


\subsubsection{Berm construction issues}

The construction of batter and berm waste dumps on mining sites typically follows the procedure shown in Figure 13. The lifts are constructed by end tipping of waste by haul trucks on the first lift out to the planned footprint area. A crest bund is maintained for safety by a bulldozer working at the active tip face, and it also keeps the dump area level. The second lift is constructed by ensuring the tip face is stepped in from the crest of the first lift, so that the angle of repose materials can be dozed down to the agreed closure gradients and that a berm remains between each lift.
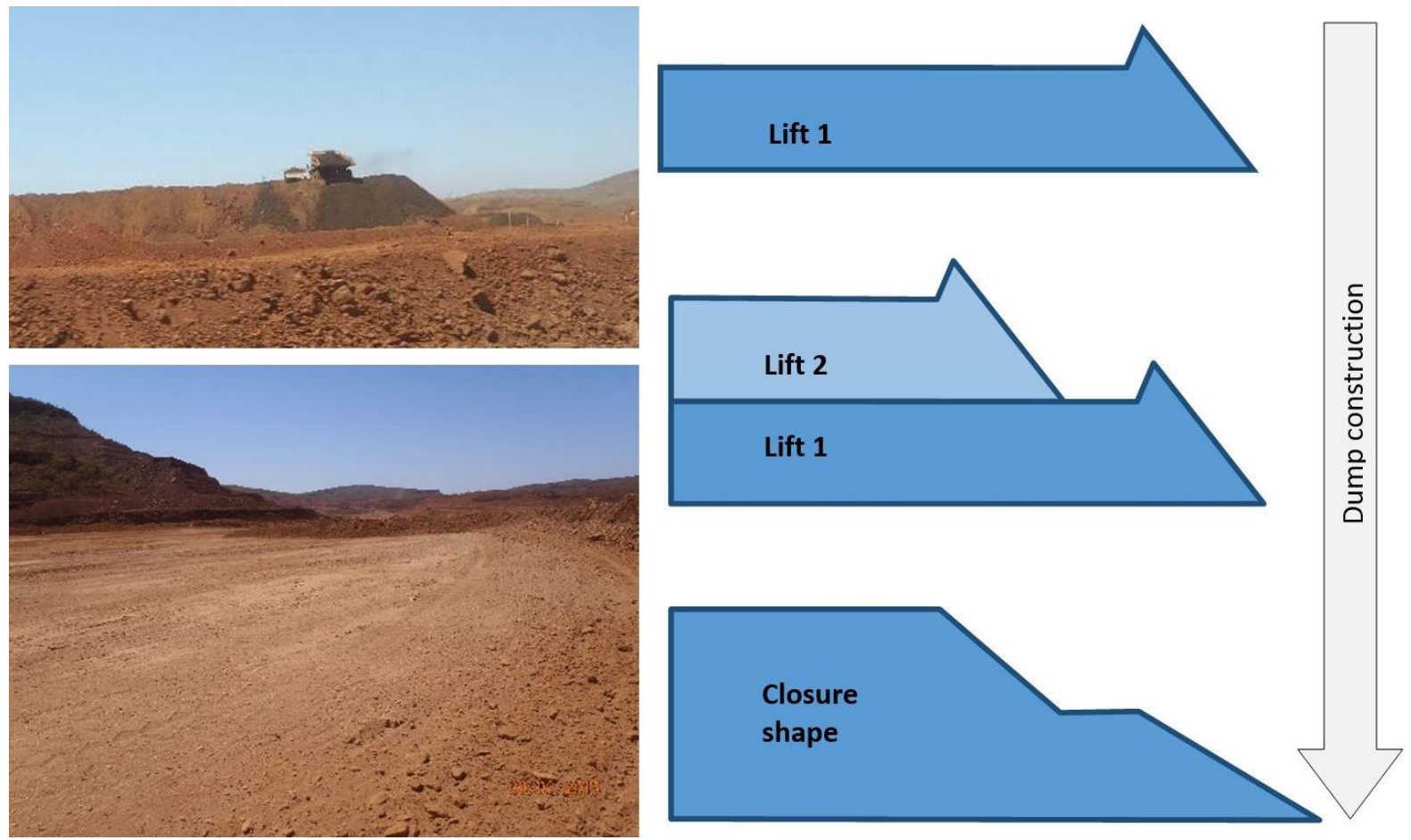

Figure 13 Waste landform construction

Although dump tops can be kept level by controlling operator skill and survey support, the machinery is not always equipped with laser levelling devices so that even the most carefully constructed dump tops have undulations. Hence, berms also tend to have undulations that create low points that can cause failure. As an example of this, Figure 14 illustrates an assessment of the causes of waste dump batter blowouts (their locations indicated by the stars) for a dump in the Pilbara.

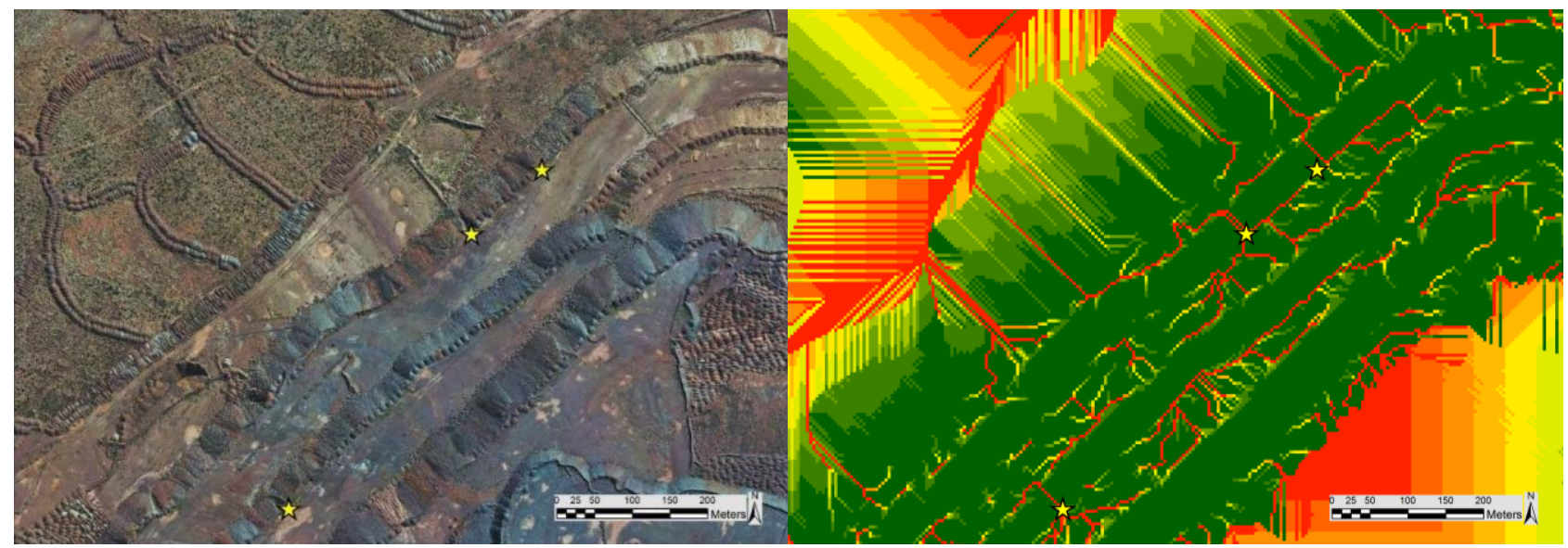

(a)

(b)

Figure 14 (a) Points of batter failure (indicated by stars) thought to be associated with geological properties; (b) a flow accumulation analysis of the same area 
It was initially assumed that the basis of the batter failures was the different erodibilities of the different wastes present on the batter surface. However, it was shown through a desktop assessment of flow accumulation, based on LiDAR data for the dump and surrounding areas, that the cause of the blowouts was the unevenly constructed berms that were directing large volumes of runoff to several discrete low points that eventually breached the crest bund during storm events, causing the blowouts, and eroding the lower batters. This is a symptom of failure to link mine operations and closure objectives, and such issues are best addressed by ensuring berms are constructed level if they indeed need to remain in the final rehabilitation shape.

\section{Discussion}

It is the authors' observation that berm failure by sediment deposition, overtopping, runoff concentration, and inadequate construction techniques are common. A recent case study reported by Howard and Lowe (2014) shown in Figure 15 typifies these processes where the toe of the upper batter is the area of maximum sediment deposition. Over a time period of only a few years, the original back sloping berm shape had filled to form a forward sloping berm (Figure 15 inset). The unevenly filled berm has also caused runoff from the smaller rills on the upper lift to be discharged onto the lower batter as more concentrated flows, creating more widely spaced and larger rills and gullies on the lower slope.

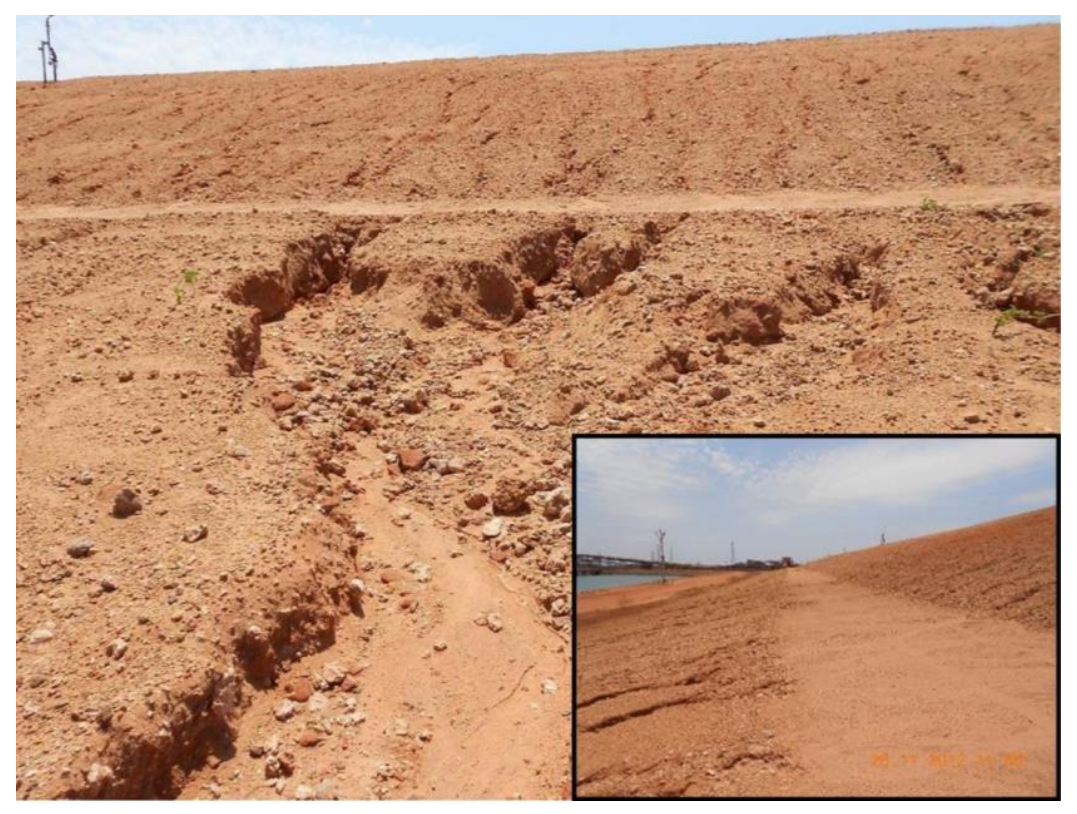

Figure 15 Waste landform rilled upper batter, and gullied lower berm, and filled forward sloping berm (inset)

In many cases it is possible to eliminate berms altogether from a landform design. By doing so, the risk of rehabilitation and closure failure can be significantly reduced. Ways in which elimination of berms can be justified in a design includes:

- Assessment of the erodibility of surface materials and use of batter profiles without berms if erosion rates are acceptably low. This can often be achieved with rocky wastes in low to moderately erosive environments (Howard et al. 2011a), (Figure 16).

- Modification of the surface materials by addition of durable waste rock or tree debris. In many cases, additional stabilising elements, such as rock, significantly increase stable slope lengths, and can alter the mechanisms that control erosion (i.e. transport capacity or detachment capacity) (Howard et al. 2010; Howard et al. 2011b), (Figure 17).

- Modification of the slope shape. For some materials, use of concave slope profiles have been seen to produce excellent rehabilitation results (Howard et al. 2011b), (Figure 18). 

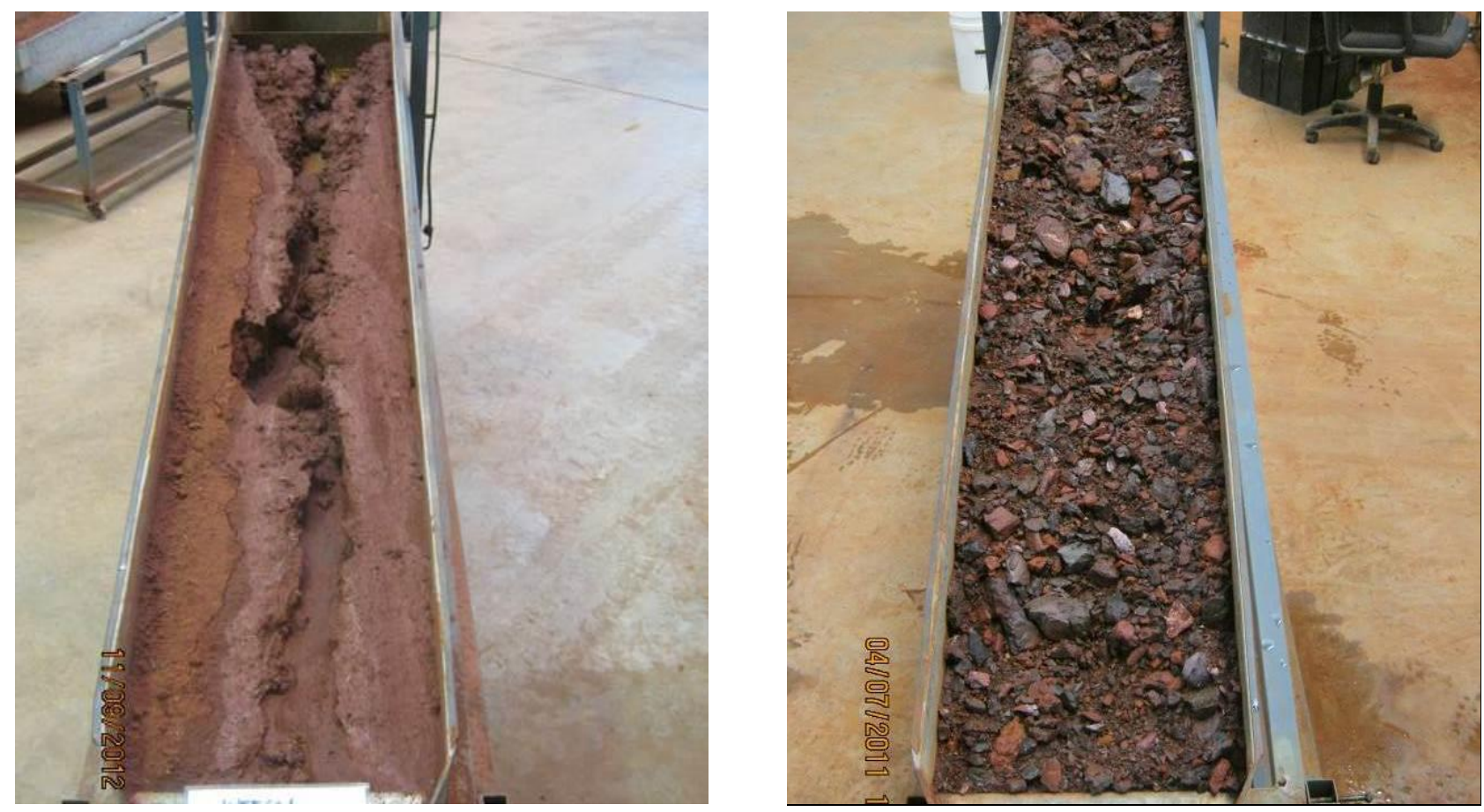

Figure 16 Flumes used to assess erodibility of a material via rill detachment

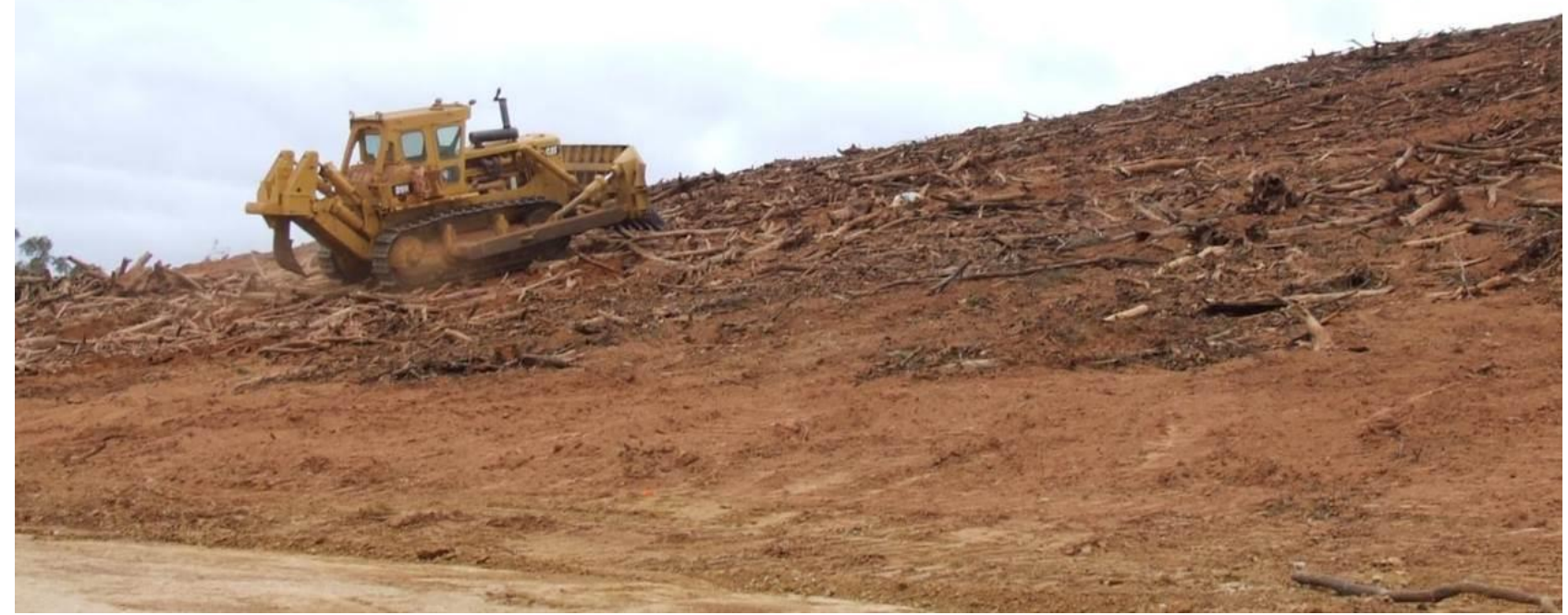

Figure 17 Addition of tree debris to increase erosion resistance of a batter slope (eliminating berm)

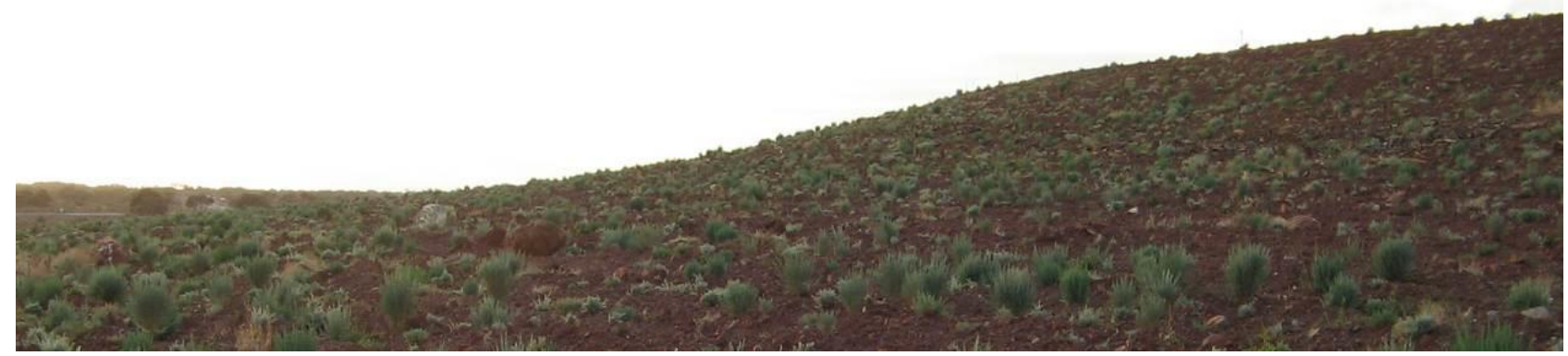

Figure 18 Concave slope profile (designed based on measurements of erodibility) used to stabilise a waste dump batter in the Goldfields (no berm required) 
Where berms are used within a design, their design capacity must be clearly established, and must include both the capacity to store runoff and eroded sediment. These assessments can be underpinned by runoff and erosion studies of the available materials. It is noted that in the cases where the authors have designed berms with sufficient storage capacity, the required berm width typically greatly exceeded the widths assumed by mine planners prior to the assessment.

\section{Conclusion}

Berms remain a persistent feature in waste dump designs as they are perceived to reduce slope length, and that in turn provides a level of protection against future batter erosion by partitioning the slope into shorter batter lengths. Level or backsloping berms are commonly used. Underpinning this is the belief that the berms will be an unchanging feature. This is not true, and berms begin to evolve immediately after construction is completed. Over the short to medium term, they trap sediment and can have a beneficial effect. Over longer periods, berms fill with sediment and overtop. The time it takes to overtop depends on the material, the size of the berm, and the climate. Once a berm is breached, previously hydraulically disconnected batter sections become a connected flow network that delivers large volumes of runoff from upper slopes to lower slopes that were never designed to withstand them. This process can be caused, or contributed to, by construction techniques.

Although berms may provide stability for waste landforms in the short term, conditions will alter in the long term and berms will eventually increase the likelihood of flow concentration, resulting in gully development and eventual slope failure. The key to designing stable landforms is to create surfaces that are not prone to high rates of erosion or rapid and irreversible changes in surface hydrology. When storm events do create surface flows, these resilient surfaces are more able to withstand stresses applied to the surface via runoff. To achieve this, landform shapes, including berms if they are used, need to be designed on the basis of the prevailing climate, and the properties of the available materials determined from characterisation of the erodibility and runoff capacity of the site's soils and wastes.

\section{References}

Govers, G \& Poesen, J 1988, 'Assessment of the Interrill and Rill Contributions to Total Soil Loss from an Upland Field Plot', Geomorphology, vol. 1, no. 4, pp. 343-354.

Howard, E \& Lowe, S 2014, 'Innovative Rehabilitation of Marine Dredge Spoil', in Proceedings of the Ninth International Conference on Mine Closure, University of the Witwatersrand, Johannesburg.

Howard, EH \& Roddy, BP 2012, 'Evaluation of the Water Erosion Prediction Project (WEPP) model: validation data from sites in Western Australia', in Fourie, AB \& Tibbett, M (eds), Proceedings of the Seventh International Conference on Mine Closure, Australian Centre for Geomechanics, Brisbane, pp. 81-92.

Howard, EH, Shemeld, J \& Loch, RJ 2010, “Ramelius Resources' Wattle Dam Project: Achieving bond reduction through leading practice', in Proceedings Goldfields Environmental Management Workshop, Goldfields Environmental Management Group, Kalgoorlie-Boulder, pp. 236-246.

Howard, EH, O'Kane, M, \& Loch, R 2011a, 'Emerging trends in the development of stable mine waste landforms and cover systems for reactive materials', in LC Bell \& B Braddock (eds), Proceedings of the Seventh Australian Workshop on Acid and Metalliferous Drainage, Goldfields Environmental Management Workshop, JKTech Pty Ltd.

Howard, EH, Loch, RJ \& Vacher, CV 2011b, 'Evolution of landform design concepts', Mining Technology, vol. 120, no. 2, pp. 112-117.

Loch, RJ \& Vacher, CA 2006, 'Assessing and managing erosion risk for constructed landforms on minesites', in Proceedings of the Goldfields Environmental Management Workshop 2006, Goldfields Environmental Management Group, Kalgoorlie-Boulder, pp. 121-127.

Loch, RJ \& Willgoose, GR 2000, 'Rehabilitated landforms: designing for stability', in Proceedings of the 2000 Workshop on environmental management in arid and semi-arid areas, Goldfields Land Rehabilitation Group, Kalgoorlie-Boulder, pp. 39-44.

Robinson, M, Howard, E \& Berghofer, P 2014, 'Case study: Using large-scale field plots to monitor erosion of waste dump batters at Birla Nifty Copper Operation', in Proceedings Goldfields Environmental Management Workshop, Kalgoorlie-Boulder.

Stevens, T 2006, 'The development of key performance indicators for progressive rehabilitation at the Murrin Murrin nickel/cobalt operation', in Proceedings of the Goldfields Environmental Management Workshop, Goldfields Environmental Management Group, Kalgoorlie-Boulder, pp. 112-120.

Vacher, CA, Raine, SR \& Loch, RJ 2004, 'Tunnel erosion in waste rock dumps', in Proceedings of the Goldfields Environmental Management Workshop, Goldfields Environmental Management Group, Kalgoorlie-Boulder, pp. 153-158. 